\title{
The Role of Suggestions in Hypnosis for Chronic Pain: A Review of the Literature
}

\author{
Tiara Dillworth* and Mark P. Jensen
}

Department of Rehabilitation Medicine, University of Washington, Seattle, Washington, USA

\begin{abstract}
Several controlled trials have demonstrated that hypnosis is an efficacious treatment for chronic pain. However, less attention has been given to the specific procedures and suggestions used in hypnotic treatments in research. The goal of this review was to address the issue of differences in the content of hypnotic suggestions, including pain management suggestions, non-pain related suggestions, and posthypnotic suggestions, in the context of published clinical trials of hypnosis for chronic pain management. This review focused on the types of suggestions used in twenty five studies comparing hypnosis to active treatments (e.g., relaxation, biofeedback), non-treatment control groups (e.g., standard care/wait-list control, supportive attention), or both in adult populations with various chronic pain conditions. Overall, these studies found hypnosis to be more effective than non-treatment control groups and similarly effective when compared to active treatments on pain-related outcomes when either pain-related suggestions or non-pain related suggestions were used. However, for studies that included both pain-specific and non-pain related suggestions, hypnosis was found to be superior to active treatments on a variety of pain-related outcomes.
\end{abstract}

Keywords: Hypnosis, hypnotic analgesia, chronic pain.

\section{INTRODUCTION}

The interest in hypnosis or hypnotic analgesia as a treatment for chronic pain has been growing throughout the past century. The earliest case reports describing strategies for using hypnosis for chronic pain have been published since at least the 1950s [1,2], and controlled trials examining the efficacy of this approach began to be published in the 1970s [3, 4]. More recently, several studies have evaluated hypnosis as a treatment for pain in a large number of chronic pain conditions, including fibromyalgia $[5,6]$, multiple sclerosis (MS) [7], irritable bowel syndrome (IBS) [8, 9], headache $[10,11]$, sickle cell disease [12], spinal cord injury [13], disability-related pain [14, 15], and cancer-related pain [16].

Several recent reviews of this growing body of literature conclude that: (1) hypnosis results in greater pain reductions across a variety of chronic pain conditions and pain-related outcomes, including intensity, duration, frequency, and use of analgesic medications when compared to standard care (i.e., no treatment) or treatments that do not have hypnotic features (e.g., supportive therapy); and (2) hypnosis has similar efficacy to other treatments that have hypnotic features, such as progressive muscle relaxation, biofeedback, and autogenic training [17-21]. Although the extant reviews examine the effects of hypnosis and hypnotic analgesia, no review has yet systematically examined (and compared) specific hypnotic procedures used in published studies.

At its most basic, hypnosis treatment consists of an "induction" (usually an invitation to focus one's attention)

\footnotetext{
*Address correspondence to this author at the University of Washington, Box 359612, $3259^{\text {th }}$ Avenue, Seattle, WA 98104-2499, USA; Tel: 1-206221-4079; Fax: 1-206-616-6278; E-mail: tiara@u.washington.edu
}

followed by suggestions (usually for changes in the client's experience) [22]. Beyond this basic structure, however, there are wide variations in many features of hypnosis treatment [17]. For example, inductions can take seconds or many minutes; even up to an hour or longer. Suggestions can vary both in terms of specificity (for specific experiences versus more vague "changes") and the target of change (e.g., decreased pain, increased comfort, distraction, changes in beliefs or attitudes, increased self-efficacy, improved sleep). If the focus (or one of the foci) of hypnosis treatment is on pain reduction, suggestions could include: (1) changing sensations from pain to something else, such as numbness; (2) reductions in pain; (3) increases in comfort; (4) changes in focus of attention away from pain; and (5) increased ability to ignore pain, among others [23]. Post-hypnotic suggestions, which include suggestions made during hypnosis that the patient will experience some change in his or her experience after the session or outside of the hypnotic context, may entail linking cues for affecting pain or that the benefits of treatment will become "permanent", may or may not be included [24]. Additionally, individuals may or may not be instructed to practice self-hypnosis outside of the treatment setting, and audio recordings of the sessions may or may not be provided to individuals to help assist with home practice.

Controlled trials that have examined the efficacy of hypnosis for chronic pain management have used some or all of these many suggestions and treatment strategies. While research has demonstrated that different hypnosis suggestions affect activity in different parts of the brain [25, 26] (see review by Jensen, 2009 [18]), and it has been suggested that a tailored combination of both analgesic and non-analgesic suggestions may provide the most benefit for patients with chronic pain [21], little research has 
specifically addressed the effects of differences in the content of hypnotic suggestions on outcomes. Given that when treating individuals with chronic pain, pain reduction is sometimes viewed as less important than improvement in activity level and quality of life [27-29], for some patients non-analgesic hypnotic suggestions may be even more important for benefiting patients than suggestions for pain relief. However, this issue has not yet been discussed at length in the hypnosis literature.

The goal of this review is to address the issue of differences in the content of hypnotic suggestions in the context of published clinical trials of hypnosis for chronic pain management. Given the extensiveness of recent reviews on this topic [17-21], the purpose of this review is not to focus on describing the basic design and outcomes of the studies, with the exception of one new study that was identified during the literature search for this review [30]. Rather, this review will focus on the types of suggestions used in the various studies, including the inclusion of posthypnotic suggestions and the results of the studies based on the type(s) of suggestions given, as well as the implications of these results for future research.

The following criteria were used to determine the inclusion of studies covered in this review: (1) a controlled trial (i.e., a study that compared the effects of a hypnosis condition relative to no treatment or some other treatment condition); (2) inclusion of adults (given research that demonstrates differential responses to hypnosis in children [31, 32]; and (3) a focus on chronic pain (versus acute procedural or laboratory pain). To identify articles to include in the review, the reference sections of already published reviews were reviewed [17-21], and additional searches were conducted using PubMed and PsychInfo (using the terms hypnosis, hypnotic analgesia, and chronic pain) to identify any new articles or studies that might have been missed by the existing reviews. One controlled trial study that has been included in past reviews was excluded from the current review due to the inclusion of children in addition to adults in their sample [33].

Twenty five studies were identified that met our search criteria. Seven of these studies focused on headache $[3,10$, $11,34-37]$, four on facial pain [30,38-40], two on cancer pain [16,41], one study on osteoarthritis pain [42], two on disability-related pain [7, 13], one on chest pain [43], two on low back pain $[44,45]$, four on chronic pain/fibromyalgia [5, $6,46,47]$, one on irritable bowel syndrome (IBS) [8], and one on mixed chronic pain conditions [4] (see Table 1).

First, this review will summarize the findings of the Abrahamsen et al., (2009) [30] study on hypnosis and temporomandibular disorder. Next, as described above, given that suggestions provided to patients during hypnosis can (1) be pain-specific, (2) be related to other non-pain specific issues, such as anxiety, stress, self-esteem, and sleep, or (3) include post-hypnotic suggestions that continue the gains made during hypnosis at a future time, this review will discuss these three categories of suggestions as they relate to pain-related outcomes. Finally, we will offer suggestions for future research with hypnosis for chronic pain.

\section{Recent Controlled Trial of Hypnosis for Chronic Pain}

Abrahamsen et al. (2009) [30] conducted a randomized control trial to evaluate the effects of hypnosis in 40 females with temporomandibular disorder (TMD). Participants were randomly assigned to either four 1-hour sessions of hypnosis or four 1-hour sessions of relaxation. The relaxation condition, however, had some hypnotic-like components, beginning with progressive muscle relaxation (PMR) followed by guided imagery to experience oneself in an autobiographic safe place based on individual preference. However, no specific suggestions for pain relief or comfort were provided. The hypnosis condition included an induction that contained all of the elements of the relaxation condition (PMR, guided imagery), but also included suggestions for experiencing feelings of success, calm, peace of mind, and inner strength. Participants in the hypnosis condition were then given several suggestions for pain relief and improvement in psychological symptoms, including suggestions to relax orofacial muscles, change pain perception through metaphor (e.g., changing the color of pain) and substitution (e.g., changing pain with warmth), create feelings of anesthesia, "let go" of bad memories, problems, and feelings of helplessness, and increase egostrength. Suggestions utilizing age regression were also incorporated, including anchoring good memories to stressful situations, remembering pain-free times, and imagining a future time when the individual is coping well with pain. Finally, participants in the hypnosis condition were given post-hypnotic suggestions, including the suggestion to use pain as a cue to become occupied with good memories and using the experience of muscle tension as a cue to relax. Participants in both conditions were given audio recordings for home practice.

The investigators found that the participants in the hypnosis condition reported a significantly more decreases in pain intensity and increases in use of reinterpreting pain sensations from pre- to post-treatment, relative to the relaxation group; however reinterpreting pain sensations was not found to mediate the effect of hypnosis on pain intensity. No significant differences were found for participants in the relaxation condition from pre- to post-treatment on these two outcomes. Both groups demonstrated a significant decrease in use of diverting attention, number of painful muscle sites on palpation and related pain scores, awakenings due to pain, somatization, and anxiety, and a significant increase in free jaw opening after treatment, but they did not significantly differ from each other. No change in medication use was shown for either treatment condition, and hypnotizability was not found to predict outcome for either group.

\section{Hypnotic Suggestions}

Table 2 lists the types of suggestions used in published controlled trial studies, described in as much detail as possible (given the descriptions provided in the original articles), as well as whether suggestions were provided for one of the three suggestion categories. As can be seen, most (22 of the 25 studies) used pain-specific suggestions in their hypnosis protocol, with the majority of these including suggestions for a reduction in the experience of pain $[3,5-$ $11,13,16,30,35-40,43-47]$. Thirteen studies provided suggestions that addressed other non-pain issues, such as 
Table 1. Procedural Descriptions of Controlled Trials of Hypnosis on Chronic Pain

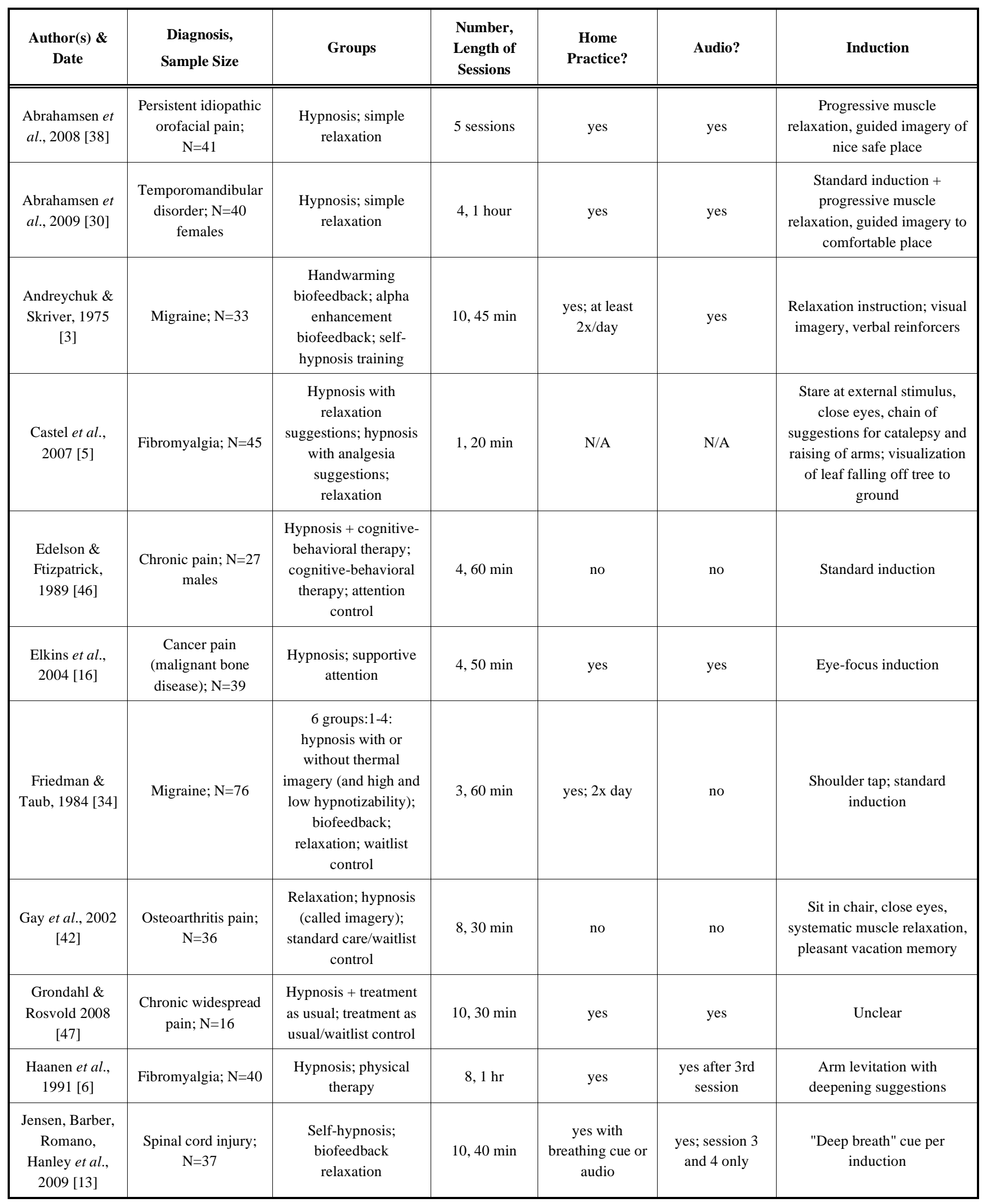


Table 1. Contd....

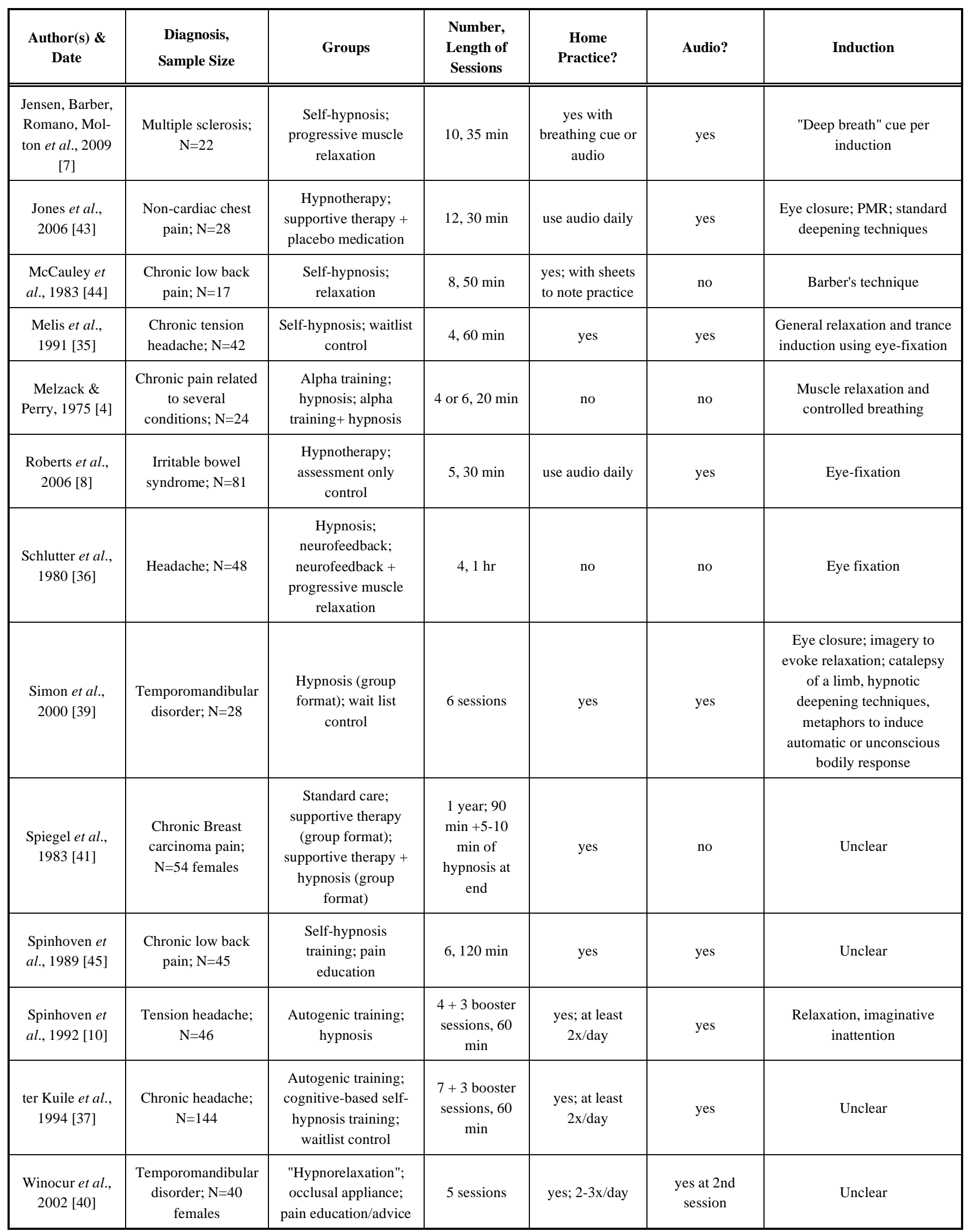


Table 1. Contd....

\begin{tabular}{|c|c|c|c|c|c|c|}
\hline $\begin{array}{c}\text { Author(s) \& } \\
\text { Date }\end{array}$ & $\begin{array}{c}\text { Diagnosis, } \\
\text { Sample Size }\end{array}$ & Groups & $\begin{array}{c}\text { Number, } \\
\text { Length of } \\
\text { Sessions }\end{array}$ & $\begin{array}{c}\text { Home } \\
\text { Practice? }\end{array}$ & Audio? & Induction \\
\hline \hline $\begin{array}{c}\text { Zitman } \text { et al., } \\
1992[11]\end{array}$ & $\begin{array}{c}\text { Tension headache; } \\
\text { N=79 }\end{array}$ & $\begin{array}{c}\text { Autogenic training; } \\
\text { hypnosis; hypnosis } \\
\text { (not called that) }\end{array}$ & 8,30 min & yes & yes & Trance induction \\
\hline
\end{tabular}

stress management, improved sleep, increased self-efficacy, increased feelings of well-being, and general health improvement [4-7, 13, 16, 30, 36, 38, 42-44, 47]. Two studies [7, 13] provided the option for participants to receive additional suggestions of their choosing, such as improved sleep or increased energy; however it is unclear how frequently this option was utilized in these studies. Of the 25 studies, eleven (including the two studies that provided the optional additional suggestion of the patient's choosing) used both pain-specific and non-pain related suggestions [5$7,13,16,30,36,38,43,44,47]$, whereas 13 provided only pain-specific suggestions [3, 8, 10, 11, 35-37, 39-41, 44-46], and two used only non-pain related suggestions [4, 42]. Only one study [34] did not include either pain-specific or nonpain related suggestions. Rather, in this study, participants either completed a standard induction only or a standard induction with thermal imagery, during which they were asked to imagine placing their hands in warm water and experience hand warmth during hypnosis.

\section{Neither Pain-Specific nor Non-Pain Related Suggestions}

As mentioned above, only one of the identified articles used neither pain-specific nor non-pain related suggestions [34]. These authors demonstrated no differences between four conditions (standard hypnotic induction alone, standard hypnotic induction with thermal imagery, biofeedback, relaxation), relative to a wait-list control condition, on frequency of headaches, pain intensity, or medication use in participants with chronic headache. All treatment groups were more effective than the wait-list control condition. In sum, it appears that hypnotic treatments for headache that consist merely of an induction alone or an induction plus thermal imagery (but no suggestions for pain reduction, per se, or suggestions for non-pain related changes) have similar effects to each other and to biofeedback and relaxation training. However, given the lack of other studies that have also compared these treatments to each other (and to hypnotic treatments that include pain-focused suggestions), any conclusions drawn must be considered preliminary at this time.

\section{Non-Pain Related Suggestions only}

Two studies included only non-pain related suggestions, such as remembering positive memories of movement and postural adaptation, having less fatigue, improving concentration, feeling stronger and healthier, and having more self-confidence [4, 42]. Gay and colleagues (2002) [42] showed that hypnosis using non-pain suggestions was more effective on reducing subjective pain than relaxation and a standard care control group at 4-week follow-up in patients with osteoarthritis pain. Both hypnosis and relaxation were more effective than control at 8-week follow-up (but equal to each other), hypnosis was more effective than control at 3month follow-up (relaxation did not differ from either group), and all groups were equal by 6-month follow-up. Both hypnosis and relaxation reduced the amount of pain medications used at the 8-week follow-up.

The second study by Melzack \& Perry (1975) [4] compared hypnosis, EEG biofeedback, and a combination hypnosis plus EEG biofeedback in individuals with mixed chronic pain conditions. They found that the combination group was more effective than the stand-alone treatments on reducing severe pain from before to after each treatment session. While hypnosis alone had a greater effect than EEG biofeedback alone, this difference was not statistically significant.

Based on the findings from these two studies, it appears that hypnosis may have some advantage over other active treatments, despite a lack of pain-specific suggestions in the hypnotic conditions. Also, when non-pain related suggestions are used in the hypnosis condition, there may be an additive affect when hypnosis is combined with EEG biofeedback. However, given that there were only two studies that provided only non-pain related suggestions, more research is needed to explore the effects of such treatments on pain and other outcomes in individuals with chronic pain.

\section{Pain-Specific Suggestions only}

A large number of studies (13) used pain-specific suggestions exclusively. Of these, seven studies compared hypnosis to other active treatments, including biofeedback, autogenic training, pain education, and cognitive-behavioral therapy (CBT) [3, 10, 11, 36, 40, 44, 45], three used both other active treatments and a non-active treatment control group [37, 41, 46], and three compared hypnosis to standard care/wait list control only [8, 35, 39]. For the seven studies that used an active treatment comparison, six of the seven found hypnosis to be at least as effective as the active treatment on certain pain-related outcomes $[3,11,36,40,44$, 45]. One study showed hypnosis to be more effective on reducing time to sleep onset and on problematic use of medications in patients with chronic low back pain [44], and another study evaluating hypnosis, pain education, and an occlusal appliance in individuals with TMD demonstrated hypnosis to have greater reductions in pain intensity and in palpation sensitivity compared to pain education group, but was as effective as an occlusal appliance for pain intensity. No differences were found between hypnosis and the occlusal appliance for palpitation sensitivity [40]. One study comparing pain education to hypnosis for headache found no impact for hypnotic on pain intensity [45]. However, this study did not use independent group comparisons as all 
Table 2. Description of Suggestions and Pain-Related Outcomes

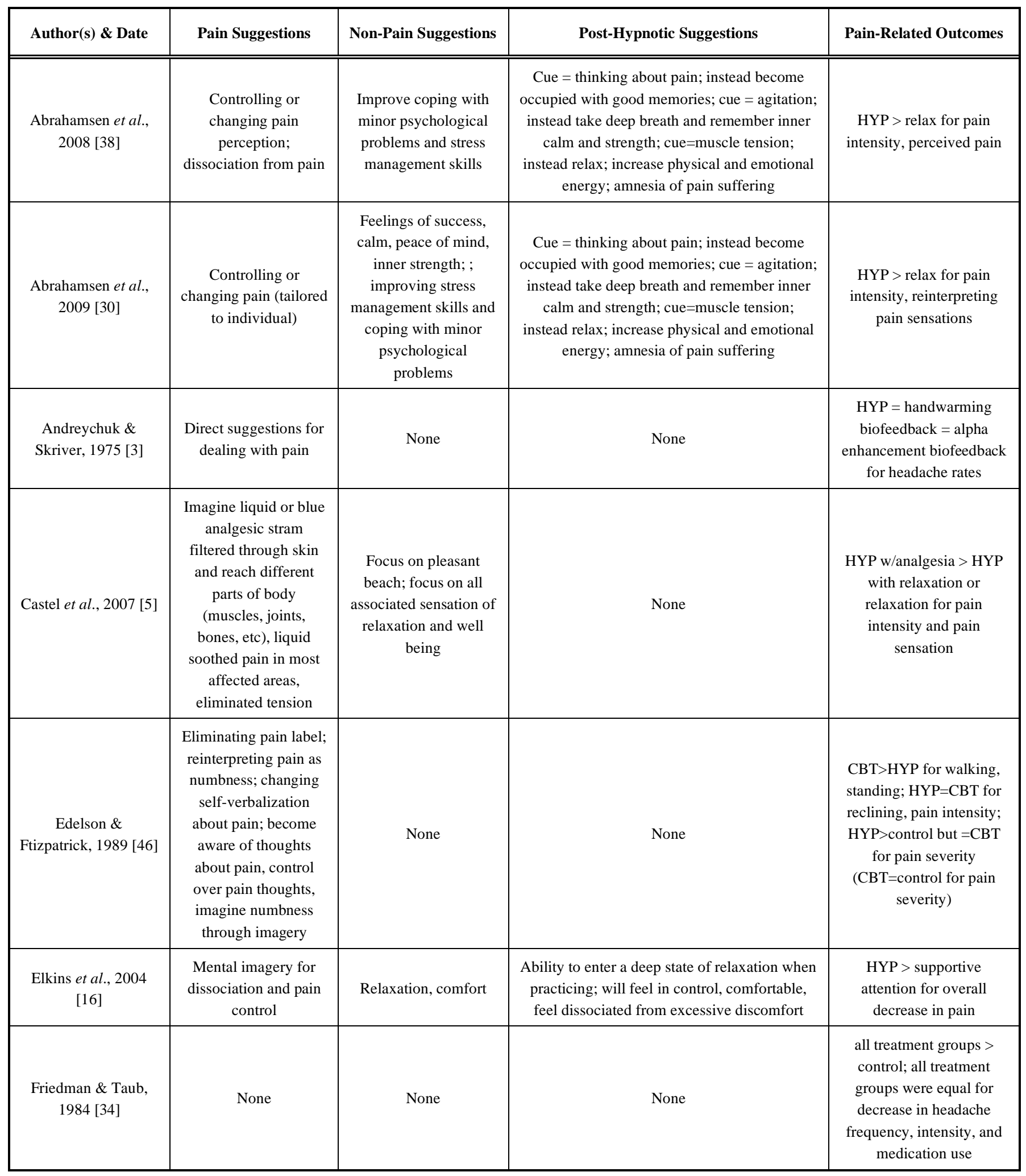


Table 2. Contd....

\begin{tabular}{|c|c|c|c|c|}
\hline Gay et al., 2002 [42] & None & $\begin{array}{l}\text { Imagine childhood } \\
\text { memory involving } \\
\text { joint mobility; For } \\
\text { each session and type } \\
\text { of memory, the } \\
\text { experimenter read a } \\
\text { standardized script that } \\
\text { evoked general images } \\
\text { of movement and } \\
\text { posture adaptation. } \\
\text { These images were } \\
\text { connected to indirect } \\
\text { suggestions of postural } \\
\text { adaptation. }\end{array}$ & None & $\begin{array}{c}\text { HYP > relaxation for } \\
\text { control and pain intensity } \\
\text { at } 4 \text { week FU; HYP=relax } \\
\text { for pain intensity at } 8 \mathrm{wk} \\
\mathrm{FU} \text {; HYP > control at } 3 \\
\text { mo FU on pain intensity; } \\
\text { all groups equal at } 6 \text { mo } \\
\text { FU }\end{array}$ \\
\hline $\begin{array}{c}\text { Haanen et al., } 1991 \\
\text { [6] }\end{array}$ & $\begin{array}{l}\text { Control of muscle } \\
\text { pain; general } \\
\text { relaxation }\end{array}$ & $\begin{array}{l}\text { Ego-strengthening; } \\
\text { improved sleep }\end{array}$ & None & $\begin{array}{l}\mathrm{HYP}>\mathrm{PT} \text { pain at post- } \\
\text { treatment and } 12 \text { week FU }\end{array}$ \\
\hline $\begin{array}{c}\text { Jensen, Barber, } \\
\text { Romano, Hanley et } \\
\text { al., } 2009 \text { [13] }\end{array}$ & $\begin{array}{l}\text { Decreased pain; deep } \\
\text { relaxation; hypnotic } \\
\text { analgesia; decreased } \\
\text { unpleasantness; } \\
\text { sensory substitution }\end{array}$ & $\begin{array}{l}\text { Possible; participants } \\
\text { given the option to } \\
\text { choose } 1 \text { non-pain } \\
\text { related suggestion }\end{array}$ & $\begin{array}{c}\text { Cue }=\text { deep breath for self-hypnosis and } \\
\text { comfort; extended analgesia; encouragement } \\
\text { of practice }\end{array}$ & $\begin{array}{c}\text { HYP = BIO for pain } \\
\text { intensity; HYP > BIO for } \\
\text { average daily pain at post- } \\
\text { treatment and 3mo FU; } \\
\text { HYP > BIO for perceived } \\
\text { control over pain at post- } \\
\text { treatment only }\end{array}$ \\
\hline $\begin{array}{c}\text { Jones } \text { et al., } 2006 \\
{[43]}\end{array}$ & $\begin{array}{l}\text { Direct suggestions } \\
\text { about pain reduction }\end{array}$ & $\begin{array}{l}\text { Chest focused; } \\
\text { normalization of } \\
\text { function of esophageal } \\
\text { motility and sensitivity } \\
\text { with imagery and } \\
\text { conditioning } \\
\text { techniques. and } \\
\text { improvement of health }\end{array}$ & None & $\begin{array}{l}\text { HYP > supportive therapy } \\
\text { for global pain } \\
\text { improvement and pain } \\
\text { intensity, reduction in } \\
\text { medication use }\end{array}$ \\
\hline $\begin{array}{l}\text { McCauley et al., } \\
1983 \text { [44] }\end{array}$ & $\begin{array}{l}\text { Change in pain image, } \\
\text { glove anesthesia, } \\
\text { hypnoplasty }\end{array}$ & $\begin{array}{c}\text { Age regression, } \\
\text { dissociation, fantasy }\end{array}$ & None & $\begin{array}{c}\text { HYP=relaxation for } \\
\text { average pain rating, length } \\
\text { of pain analog time. HYP } \\
=\text { less problematic use of } \\
\text { medication. }\end{array}$ \\
\hline $\begin{array}{c}\text { Melis et al., } 1991 \\
{[35]}\end{array}$ & $\begin{array}{c}\text { Flow-off technique: } \\
\text { transform pain into } \\
\text { sensations that are } \\
\text { easier to tolerate; } \\
\text { transfer pain to } \\
\text { another body part } \\
\text { where it is less } \\
\text { disabling }\end{array}$ & None & None & $\begin{array}{l}\text { HYP > control for \# } \\
\text { headache days, hours, } \\
\text { headache intensity }\end{array}$ \\
\hline
\end{tabular}


Table 2. Contd....

\begin{tabular}{|c|c|c|c|c|}
\hline $\begin{array}{c}\text { Melzack \& Perry, } \\
1975[4]\end{array}$ & None & $\begin{array}{l}\text { Feeling stronger and } \\
\text { healthier, greater } \\
\text { alertness and energy, } \\
\text { less fatigue, less } \\
\text { discouragement, } \\
\text { feeling of greater } \\
\text { tranquility and of being } \\
\text { able to overcome } \\
\text { things that are usually } \\
\text { upsetting and } \\
\text { worrying; being able to } \\
\text { think more clearly, to } \\
\text { concentrate, to } \\
\text { remember things, to be } \\
\text { emotionally more } \\
\text { calm, to be less tense } \\
\text { (emotionally and } \\
\text { physically), more self- } \\
\text { confident and } \\
\text { independent, less } \\
\text { fearful of failure }\end{array}$ & None & $\begin{array}{c}\text { HYP + biofeedback > } \\
\text { biofeedback alone or HYP } \\
\text { alone for severe clinical } \\
\text { pain }\end{array}$ \\
\hline $\begin{array}{c}\text { Roberts et al., } 2006 \\
{[8]}\end{array}$ & $\begin{array}{l}\text { Patient-specific; e.g. } \\
\text { constipation = } \\
\text { visualization of river } \\
\text { with speeding up } \\
\text { currents; pain = heat at } \\
\text { site of pain or } \\
\text { emanating from hand } \\
\text { placed on area; } \\
\text { encouraged to use } \\
\text { whatever images they } \\
\text { were comfortable with }\end{array}$ & None & None & $\begin{array}{l}\text { HYP }>\text { control for pain } \\
\text { and diarrhea at } 3 \text { mo only; } \\
\text { HYP = control over } 12 \\
\text { months }\end{array}$ \\
\hline $\begin{array}{c}\text { Simon et al., } 2000 \\
{[39]}\end{array}$ & $\begin{array}{l}\text { Hypnotic analgesia } \\
\text { and anesthesia }\end{array}$ & None & $\begin{array}{c}\text { Use muscle tension, pain or both as a cue for } \\
\text { automatic muscle relaxation; suggestions for } \\
\text { relapse prevention }\end{array}$ & $\begin{array}{l}\text { HYP }>\text { control pain } \\
\text { frequency, duration, } \\
\text { intensity. Gains } \\
\text { maintained at } 6 \text { mo FU }\end{array}$ \\
\hline $\begin{array}{c}\text { Spiegel et al., } 1983 \\
{[41]}\end{array}$ & $\begin{array}{c}\text { Filter out hurt by } \\
\text { imagining competing } \\
\text { sensations in affected } \\
\text { areas }\end{array}$ & None & None & $\begin{array}{c}\text { HYP, Support group > } \\
\text { standard care for reduced } \\
\text { pain and suffering; HYP > } \\
\text { support group for less } \\
\text { increase in pain over time }\end{array}$ \\
\hline $\begin{array}{c}\text { Spinhoven } \text { et al., } \\
1989 \text { [45] }\end{array}$ & $\begin{array}{c}\text { Relaxation, } \\
\text { imaginative } \\
\text { inattention, pain } \\
\text { displacement, pain } \\
\text { transformation, and } \\
\text { future oriented } \\
\text { imagery }\end{array}$ & None & None & $\begin{array}{c}\mathrm{HYP}=\mathrm{AT} \text { for medication } \\
\text { use. No improvement on } \\
\text { pain intensity }\end{array}$ \\
\hline
\end{tabular}


Table 2. Contd....

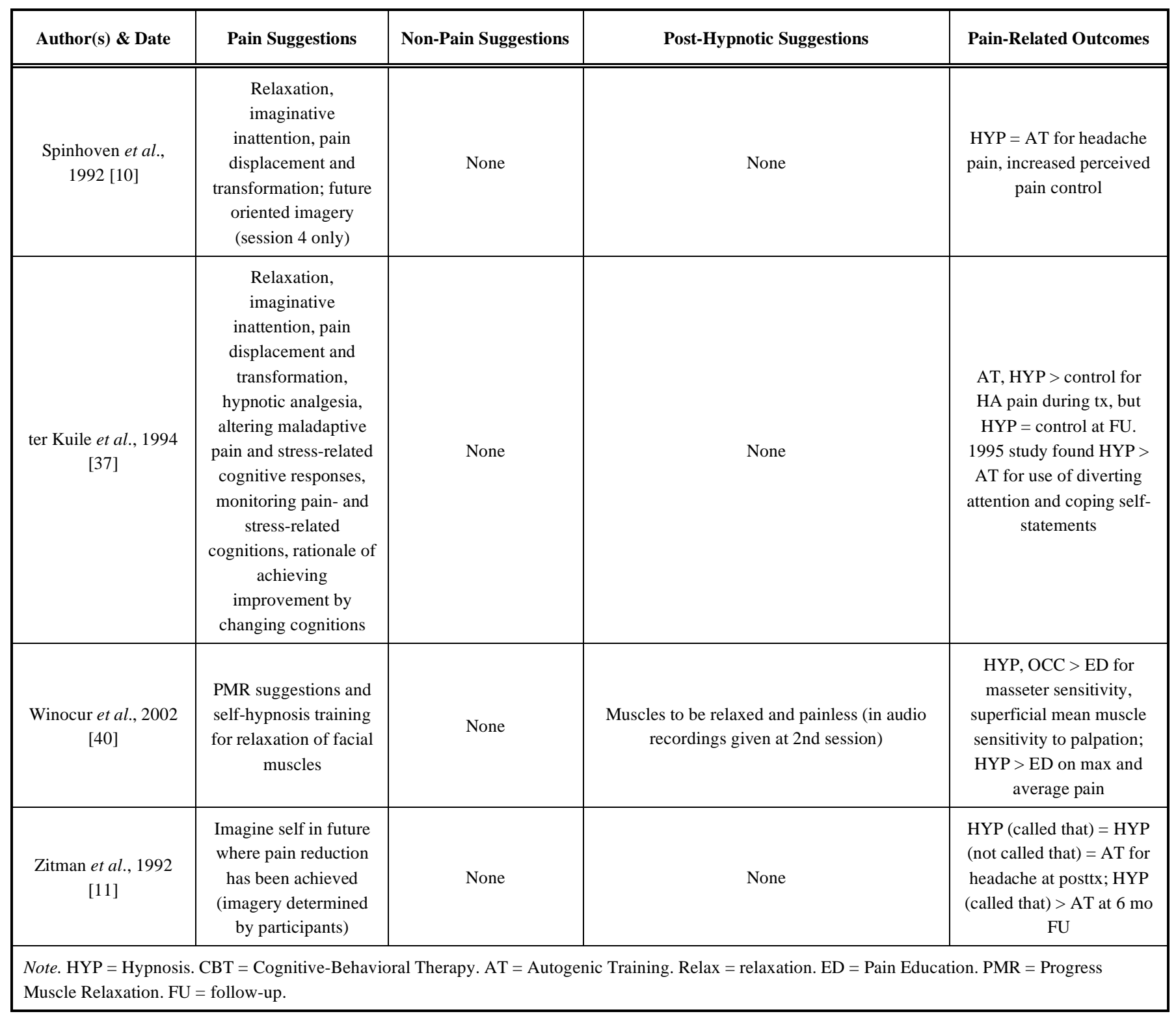

participants received both treatments (i.e., participants were assigned to receive six months of education, followed by a two-month break, followed by six months of hypnosis, or vice versa), and there was a high drop out rate, making this study more difficult to compare to others included in this section. One study including follow-up data showed hypnosis to be more effective for participants with headache at 6-month follow-up compared to autogenic training (but not at post-treatment) [11].

A mix of results was evinced in the three studies that compared hypnosis to an active treatment and a control group. One study revealed hypnosis provided as a part of a support group treatment to be more effective for preventing increases in pain over time relative to the support group alone in a sample of females with chronic breast carcinoma [41]. Edelson and Fitzpatrick (1989)[46] showed that (1) hypnosis had greater effects on pain intensity and severity compared to controls, (2) hypnosis had similar effects on pain intensity compared to CBT, but (3) found CBT to be more effective than hypnosis on improving pain-related behaviors (such as walking and standing time) in males with chronic pain. Ter Kuile et al. (1994)[37] showed hypnosis and autogenic training to be more effective than a wait-list control for pain during treatment in a sample of patients with headache, but found no differences at follow-up. A secondary data analysis paper [48] demonstrated participants in the hypnosis group were more likely to use diverting attention and coping-self-statements as coping strategies; however the meditational role of these strategies on pain reduction was inconclusive. All three studies that compared hypnosis to waitlist control found hypnosis to be significantly more effective on pain-related outcomes, including pain frequency, duration, and intensity, compared to the control groups used in these studies [8, 35, 39]. However, one study showed no differences at a 12-month follow-up in patients with irritable bowel syndrome [8].

In sum, hypnotic treatments that include only painspecific suggestion appear to be more effective than various 
control groups at affecting pain-related outcomes, although the improvements in pain (relative to control treatment) may be lost over time [8, 37]. Hypnosis appears to be at least as effective compared to active treatments, with some advantages found for hypnosis on less pain over time [11, 41], pain intensity [40] use of coping strategies [48], and sleep [44], but (in one study) less advantage on specific painrelated behaviors [37].

\section{Both Pain-Specific and Non-Pain Related Suggestions}

Finally, nine studies included both pain-specific and nonpain related suggestions. Three studies compared hypnosis with these suggestions to a non-active control group, including supportive attention [16], treatment as usual/waitlist control [47], and supportive therapy with placebo medication [43]. Six studies compared hypnosis to an active treatment, including simple relaxation $[5,30,38]$, physical therapy [6], EMG biofeedback-assisted relaxation [13] and PMR [7]. For the three studies comparing hypnosis to a nonactive control group, overall results showed hypnosis to be more effective than control. One study found these gains were maintained at a 1-year follow-up in patients with chronic widespread pain [47].

All six studies evaluating hypnosis compared to active treatment found hypnosis to be more effective than the active treatments on several outcomes, including pain intensity (with the exception of Jensen et al., 2009 [13]), medication use, and use of pain-specific coping strategies. Additionally, Abrahamsen et al., 2008 [38] found greater beneficial effects for TMD among participants with higher hypnotizability, and Haanen et al., (1991) [6] showed that treatment gains were maintained at a 12-week follow-up for participants with fibromyalgia. One study [13] demonstrated hypnosis compared to EMG biofeedback-assisted relaxation training to be more effective on average daily pain at post-treatment and 3-month follow-up and on perceived control over pain at post-treatment, but discovered no differences between hypnosis and biofeedback on pre- to post-treatment session pain intensity in individuals with spinal cord injury (both groups significantly reduced intensity during the treatment sessions).

Only one study compared the effects of pain-specific and non-pain specific suggestions in patients with fibromyalgia [5]. Participants were either assigned to hypnosis with analgesic suggestions, hypnosis with relaxation, or relaxation training. Results showed that hypnosis with analgesia suggestions had a larger effect on pain intensity and pain sensation than those in either of the other treatment conditions. No differences were found for the affective dimension of pain between any of the three treatment conditions, and there were no differences between hypnosis with relaxation and relaxation only on any of the outcomes. While this study used both pain-specific and other non-pain focused (i.e., general relaxation) suggestions, participants were presented with either type, not both, so these results cannot be directly compared to the other studies that included both types of suggestions.

Taken as a whole, it appears hypnosis that includes both pain-specific and non-pain focused suggestions seems to be more effective than both control and active treatments for several pain-related outcomes. This effect appears to be notably more consistent for these studies than in studies comparing hypnosis using either (or neither) type of suggestions to active treatments. This suggests the possibility that inclusion of both types of suggestions may increase the benefits achieved from hypnosis for chronic pain, particularly when compared to an active treatment. It is also of note that studies incorporating both types of suggestion have been published in the past five years (with the exception of Haanen et al., 1991 [6]). This may indicate the benefit of including both types is becoming more evident. However, more research is needed to explore this further.

\section{Post-Hypnotic Suggestions}

Seven studies included post-hypnotic suggestions as part of the hypnosis treatment for chronic pain $[7,13,16,30,38$ 40]. Abrahamsen and colleagues [30, 38] incorporated the use of cues for the post-hypnotic suggestions. For example, participants were instructed to become occupied with good memories when they noticed they were thinking about pain (cue), to take a deep breath and remember their inner calm and strength when they became agitated (cue), or to relax when they experienced muscle tension (cue). Elkins et al. (2004) [16] suggested that participants be able to enter a deep state of relaxation when practicing hypnosis, and will feel in control, comfortable, and dissociated from excessive discomfort. In two studies, Jensen et al. [7, 13] asked participants to "take a deep breath, hold it for a moment, and then let it go" just before every hypnosis session, and then to use this as a cue to begin self-hypnosis practice when they wished to feel more comfortable. Additionally, suggestions were given to extend analgesic effects past the time of hypnosis (e.g., for "hours to days to years" after hypnosis) and to encourage practice on a regular basis. Simon et al. (2002) [39] told patients to use perceived muscle tension and pain as cues for automatic muscle relaxation and provided post-hypnotic suggestions for relapse prevention. Winocur and colleagues (2002) [40] gave post-hypnotic suggestions for muscles to be "relaxed and painless." These posthypnotic suggestions were given in an audio recording provided to participants after the second treatment session.

Five of the seven studies included both pain-specific and non-pain related post-hypnotic suggestions, with findings overall suggesting that hypnosis treatment that included both of these suggestion types to be more effective than active treatment $[7,13,30,38,40]$ or control [16] on several painrelated outcomes (with the exception of hypnosis compared to biofeedback on pain intensity as described above; Jensen et al., 2009 [13]). These five studies also used both types of suggestions during hypnosis. The remaining two studies [39, 40] used pain-specific post-hypnotic suggestions only, with results showing hypnosis to be more effective than wait-list control but at least as effective as an active treatment. Overall, it appears that hypnotic treatments that include both pain-specific and non-pain related post-hypnotic suggestions are more effective on several pain outcomes when compared to both active treatments and non-treatment control. When studies only utilized pain-specific post-hypnotic suggestions, hypnosis performed better than control and as well as active treatment. It is important to note that all of these studies used the same types of suggestions during the course of hypnosis as well as in the post-hypnotic suggestions, thus it is difficult 
to conclude what effects the addition of post-hypnotic suggestions may have had.

\section{Other Procedural Factors}

There are a number of additional treatment-related factors that may impact the effectiveness of hypnosis in relieving pain-related outcomes, including encouragement of home practice and use of audio recordings to assist individuals develop their self-hypnosis skills. In fact, 17 or the 25 studies in this review gave participants audio recordings, and 20 of the 25 studies gave instructions for participants to practice outside of the treatment session, including listening to audio recordings using cues to begin their practice, reviewing written instructions, and practicing multiple times a day (see Table 1). Additionally, studies varied in the type of induction used, including eye fixation, muscle relaxation, guided imagery, catalepsy of a limb, and various combinations of these approaches, among others. Moreover, variations in number of treatment sessions and session length are notable, ranging from a single 20-minute session to one year of 90-minute group sessions with 5-10 minutes of hypnosis added at the end. Two studies performed hypnosis in a group format $[39,41]$. It is possible that any and all of these factors might influence differences in outcome; however this has not been systematically explored in detail. More examination of the role of these factors may be important to determine their contribution to change in pain-related outcomes.

\section{DISCUSSION}

Overall, this review has highlighted the types of suggestions found in 25 control trials on chronic pain and has explored the relation between type of suggestion and outcomes. As previous reviews have concluded, the findings indicate that hypnosis has a greater beneficial effect on outcomes when compared to wait list and "minimally effective" control conditions such as supportive attention, and a similar, if not greater effect compared to different active treatments. Moreover, there appears to be some evidence to support inclusion of both pain-specific and nonpain related suggestions, as studies using both types of suggestions appeared to have greater benefits on pain-related outcomes, both in comparison to control groups and active treatments, than studies that did not. As stated in the introduction, it may be important to provide suggestions that address not only pain, but other factors that can affect quality of life. It appears, at least based on the research conducted thus far, that a combination of suggestions may provide a more consistent benefit of improving pain-related outcomes. This is a question that should be addressed in future research.

More recently, studies have begun including posthypnotic suggestions as part of their hypnosis treatment. Theoretically, these types of suggestions allow individuals to experience the benefits of hypnosis at a future time. While studies that included post-hypnotic suggestions in the current review demonstrated benefit on pain-related outcomes, it is unclear how much the addition of post-hypnotic suggestions adds to the gains made in hypnotic treatment. To our knowledge, no study has yet compared the relative efficacy of hypnosis treatment that includes post-hypnotic suggestions to hypnosis treatment that does not include post- hypnotic suggestions. Additionally, based on the publication dates of these studies that included post-hypnotic suggestions as a part of the hypnosis treatment, it appears that the used of such suggestions may be a relatively new addition to hypnotic procedures, at least in the research realm. Clearly more research is needed to determine if these suggestions are linked to improvements in pain-related outcomes.

It is possible that other procedural factors, such as use of audio recordings, number of sessions, and induction type, can affect outcome. Currently, it remains unknown what are the necessary components in hypnotic treatments to impact pain-related outcomes. By continuing exploration of these components, we will better understand what will most likely benefit patients suffering with long-standing pain conditions [49].

As has been noted elsewhere [17, 49], we found a lack of standardized procedures in research for testing the effects of hypnosis. By providing detailed descriptions of hypnotic procedures in publications, researchers can better replicate and develop effective protocols for pain management. Jensen and Patterson (2005) [49] have outlined the basic components of a hypnosis treatment that includes a standardized induction and pain-related suggestions, a minimum 20 minute time length, 4 or more sessions for hypnosis treatment (with 3 or less being "brief hypnosis"), and recommendation for home practice with or without audio recordings. In addition to these guidelines, the current review may suggest the addition of non-pain related suggestions, particularly when comparing hypnosis to an active treatment condition. Regardless, providing clear details and examples of the types of suggestions given will make replication and extension easier for future research. Additionally, more recent research has begun to include the use of post-hypnotic suggestions. This too would benefit from clearer description and development of standard procedures for implementing these in the treatment.

\section{CONCLUSION}

Chronic pain is a complex phenomenon and is rarely managed with a single type of treatment. Overall, the findings show hypnosis to be a viable and effective option for managing chronic pain, and given its lack of substantial side effects and potential cost-effective benefits [50] it remains an attractive option. Indeed, research studying treatment satisfaction with hypnosis has found high rates of satisfaction among participants, even when a reduction in pain was not achieved [51]. This suggests that greater uniformity among research studies may lead to a better understanding of both the role of different types of suggestions on pain-related outcomes, but also to gaining insight into which components of hypnosis are critical to instigate change.

\section{CONFLICT OF INTEREST}

M.P.J. has received research support, consulting fees, or honoraria in the past year from Analgesic Research, Consultants in Behavioral Research, Endo, Lilly, Medtronic, Merck, Pfizer, US Department of Education, US Department of Veterans Affairs, and the US National Institutes of Health 


\section{ACKNOWLEDGEMENTS}

This research was supported in part by the National Institutes of Health Grant R01HD057916-01 awarded to Dawn Ehde, PI.

\section{REFERENCES}

[1] Barber TX. Toward a theory of pain: relief of chronic pain by prefrontal leucotomy, opiates, placebos, and hypnosis. Psychol Bull 1959; 56: 430-60.

[2] Erickson MH. Hypnosis in painful terminal illness. J Ark Med Soc 1959; 56(2): 67-71.

[3] Andreychuk T, Skriver C. Hypnosis and biofeedback in the treatment of migraine headache. Int J Clin Exp Hypn 1975; 23(3): 172-83.

[4] Melzack R, Perry C. Self-regulation of pain: the use of alphafeedback and hypnotic training for the control of chronic pain. Exp Neurol 1975; 46(3): 452-69.

[5] Castel A, Perez M, Sala J, Padrol A, Rull M. Effect of hypnotic suggestion on fibromyalgic pain: comparison between hypnosis and relaxation. Eur J Pain 2007; 11(4): 463-8.

[6] Haanen HC, Hoenderdos HT, van Romunde LK, et al. Controlled trial of hypnotherapy in the treatment of refractory fibromyalgia. J Rheumatol 1991; 18(1): 72-5.

[7] Jensen MP, Barber J, Romano JM, et al. A comparison of selfhypnosis versus progressive muscle relaxation in patients with multiple sclerosis and chronic pain. Int J Clin Exp Hypn 2009; 57(2): 198-221.

[8] Roberts L, Wilson S, Singh S, Roalfe A, Greenfield S. Gut-directed hypnotherapy for irritable bowel syndrome: piloting a primary care-based randomised controlled trial. $\mathrm{Br}$ J Gen Pract 2006; 56(523): 115-21.

[9] Simren M, Ringstrom G, Bjornsson ES, Abrahamsson $H$. Treatment with hypnotherapy reduces the sensory and motor component of the gastrocolonic response in irritable bowel syndrome. Psychosom Med 2004; 66(2): 233-8.

[10] Spinhoven P, Linssen AC, Van Dyck R, Zitman FG. Autogenic training and self-hypnosis in the control of tension headache. Gen Hosp Psychiatry 1992; 14(6): 408-15.

[11] Zitman FG, van Dyck R, Spinhoven P, Linssen AC. Hypnosis and autogenic training in the treatment of tension headaches: a twophase constructive design study with follow-up. J Psychosom Res 1992; 36(3): 219-28

[12] Dinges DF, Whitehouse WG, Orne EC, et al. Self-hypnosis training as an adjunctive treatment in the management of pain associated with sickle cell disease. Int J Clin Exp Hypn 1997; 45(4): 417-32.

[13] Jensen MP, Barber J, Romano JM, et al. Effects of self-hypnosis training and EMG biofeedback relaxation training on chronic pain in persons with spinal-cord injury. Int J Clin Exp Hypn 2009; 57(3): 239-68

[14] Jensen MP, Barber J, Hanley MA, et al. Long-term outcome of hypnotic-analgesia treatment for chronic pain in persons with disabilities. Int J Clin Exp Hypn 2008; 56(2): 156-69.

[15] Jensen MP, Hanley MA, Engel JM, et al. Hypnotic analgesia for chronic pain in persons with disabilities: a case series. Int $\mathrm{J}$ Clin Exp Hypn 2005; 53(2): 198-228.

[16] Elkins G, Cheung A, Marcus J, Palamara L, Rajab MH. Hypnosis to reduce pain in cancer survivors with advanced disease: a prospective study. J Cancer Integrat Med 2004; 2(4): 167-72.

[17] Elkins G, Jensen MP, Patterson DR. Hypnotherapy for the management of chronic pain. Int J Clin Exp Hypn 2007; 55(3): 275-87.

[18] Jensen MP. Hypnosis for chronic pain management: a new hope. Pain 2009; doi:10.1016/j.pain.2009.06.027 (in press).

[19] Jensen M, Patterson DR. Hypnotic treatment of chronic pain. J Behav Med 2006; 29(1): 95-124.

[20] Patterson DR, Jensen MP. Hypnosis and clinical pain. Psychol Bull 2003; 129(4): 495-521.

[21] Stoelb BL, Molton IR, Jensen MP, Patterson DR. The efficacy of hypnotic analgesia in adults: a review of the literature. Contemp Hypn 2009; 26(1): 24-39.

[22] Green JP. Beliefs about hypnosis: popular beliefs, misconceptions, and the importance of experience. Int J Clin Exp Hypn 2003; 51(4): 369-81.
[23] Erickson M, Rossi E, Rossi S. Hypnotic realities: the induction of clinical hypnosis and forms of indirect suggestion. New York: Irvington 1976.

[24] Yapko MD. Trancework: an introduction to the practice of clinical hypnosis. 3rd ed. New York: Brunner-Routledge 2003.

[25] Hofbauer RK, Rainville P, Duncan GH, Bushnell MC. Cortical representation of the sensory dimension of pain. J Neurophysiol 2001; 86(1): 402-11.

[26] Rainville P, Duncan GH, Price DD, Carrier B, Bushnell MC. Pain affect encoded in human anterior cingulate but not somatosensory cortex. Science 1997; 277(5328): 968-71.

[27] Turk DC, Flor H. Chronic pain: a biobehavioral perspective. In: Turk RJGDC, editor. Psychosocial factors in pain: critical perspectives. New York: Guilford Press 1999; pp. 18-34.

[28] Turk DC, Okifuji A. Treatment of chronic pain patients: Clinical outcomes, cost-effectiveness, and cost-benefits of multidisciplinary pain centers. Crit Rev Phys Rehabilit Med 1998; 10: 181-208.

[29] Turk DC, Okifuji A. Interdisciplinary approach to pain management: philosophy, operations, and efficacy. In: Ashburn MA, Rice LJ, Eds. The management of pain. Baltimore: ChurchillLivingstone 1998; pp. 235-48.

[30] Abrahamsen R, Zachariae R, Svensson P. Effect of hypnosis on oral function and psychological factors in temporomandibular disorders patients. J Oral Rehabil 2009; 36(8): 556-70.

[31] Gardner GG. Hypnosis with children. Int J Clin Exp Hypn 1974; 22(1): 20-38.

[32] Milling LS, Costantino CA. Clinical hypnosis with children: first steps toward empirical support. Int J Clin Exp Hypn 2000; 48(2): 113-37.

[33] Anderson JA, Basker MA, Dalton R. Migraine and hypnotherapy. Int J Clin Exp Hypn 1975; 23(1): 48-58

[34] Friedman H, Taub HA. Brief psychological training procedures in migraine treatment. Am J Clin Hypn 1984; 26(3): 187-200.

[35] Melis PM, Rooimans W, Spierings EL, Hoogduin CA. Treatment of chronic tension-type headache with hypnotherapy: a single-blind time controlled study. Headache 1991; 31(10): 686-9.

[36] Schlutter LC, Golden CJ, Blume HG. A comparison of treatments for prefrontal muscle contraction headache. $\mathrm{Br} \mathrm{J}$ Med Psychol 1980; 53(1): 47-52.

[37] Ter Kuile MM, Spinhoven P, Linssen AC, Zitman FG, Van Dyck R, Rooijmans HG. Autogenic training and cognitive self-hypnosis for the treatment of recurrent headaches in three different subject groups. Pain 1994; 58(3): 331-40.

[38] Abrahamsen R, Baad-Hansen L, Svensson P. Hypnosis in the management of persistent idiopathic orofacial pain--clinical and psychosocial findings. Pain 2008; 136(1-2): 44-52.

[39] Simon EP, Lewis DM. Medical hypnosis for temporomandibular disorders: treatment efficacy and medical utilization outcome. Oral Surg Oral Med Oral Pathol Oral Radiol Endod 2000; 90(1): 54-63.

[40] Winocur E, Gavish A, Emodi-Perlman A, Halachmi M, Eli I Hypnorelaxation as treatment for myofascial pain disorder: a comparative study. Oral Surg Oral Med Oral Pathol Oral Radiol Endod 2002; 93(4): 429-34.

[41] Spiegel D, Bloom JR. Group therapy and hypnosis reduce metastatic breast carcinoma pain. Psychosom Med 1983; 45(4) 333-9.

[42] Gay MC, Philippot P, Luminet O. Differential effectiveness of psychological interventions for reducing osteoarthritis pain: a comparison of Erikson [correction of Erickson] hypnosis and Jacobson relaxation. Eur J Pain 2002; 6(1): 1-16.

[43] Jones H, Cooper P, Miller V, Brooks N, Whorwell PJ. Treatment of non-cardiac chest pain: a controlled trial of hypnotherapy. Gut 2006; 55(10): 1403-8.

[44] McCauley JD, Thelen MH, Frank RG, Willard RR, Callen KE. Hypnosis compared to relaxation in the outpatient management of chronic low back pain. Arch Phys Med Rehabil 1983; 64(11): 54852 .

[45] Spinhoven P, Linssen AC. Education and self-hypnosis in the management of low back pain: a component analysis. $\mathrm{Br} \mathrm{J}$ Clin Psychol 1989; 28 ( Pt 2): 145-53.

[46] Edelson J, Fitzpatrick JL. A comparison of cognitive-behavioral and hypnotic treatments of chronic pain. J Clin Psychol 1989; 45(2): 316-23.

[47] Grondahl JR, Rosvold EO. Hypnosis as a treatment of chronic widespread pain in general practice: a randomized controlled pilot trial. BMC Musculoskelet Disord 2008; 9: 124. 
[48] ter Kuile BH, Spinhoven P, Linssen AC, van Houwelingen HC. Cognitive coping and appraisal processes in the treatment of chronic headache. Pain 1995; 64: 257-64.

[49] Jensen MP, Patterson DR. Control conditions in hypnotic-analgesia clinical trials: challenges and recommendations. Int J Clin Exp Hypn 2005; 53(2): 170-97.
[50] Lang EV, Benotsch EG, Fick LJ, et al. Adjunctive nonpharmacological analgesia for invasive medical procedures: a randomised trial. Lancet 2000; 355(9214): 1486-90

[51] Jensen MP, McArthur KD, Barber J, et al. Satisfaction with, and the beneficial side effects of, hypnotic analgesia. Int J Clin Exp Hypn 2006; 54(4): 432-47.

(C) Dillworth and Jensen; Licensee Bentham Open.

This is an open access article licensed under the terms of the Creative Commons Attribution Non-Commercial License (http://creativecommons.org/licenses/by-nc/3.0/) which permits unrestricted, non-commercial use, distribution and reproduction in any medium, provided the work is properly cited. 